\title{
AS OBJEÇÕES DE NIETZSCHE AO CONCEITO DE COISA EM SI
}

\author{
André Luís Mota Itaparica* \\ itapa71@gmail.com
}

RESUMO Entre os temas kantianos discutidos por Nietzsche, o tradicional problema do estatuto da coisa em si é particularmente relevante para a formulação de sua própria filosofia. Por esse motivo, a compreensão de Nietzsche desse problema também se tornou um dos assuntos mais debatidos e controversos entre seus intérpretes. De forma geral, tende-se a identificar na filosofia de Nietzsche uma trajetória que o levaria da admissão de um conceito de coisa em si em sua juventude até uma negação, em sua filosofia madura, da coisa em si, considerada como uma concepção contraditória. A discordância entre os comentadores surge quando se pergunta se o conceito de coisa em si que Nietzsche nega é exatamente aquilo que Kant entendia por coisa em si. Nosso trabalho pretende discutir essa questão a partir do estudo de três objeções de Nietzsche ao conceito de coisa em si, levando em consideração os aspectos históricos do problema e as soluções oferecidas pela literatura secundária.

Palavras-chave Nietzsche, Kant, coisa em si.

ABSTRACT Among the Kantian issues discussed by Nietzsche, the traditional problem of the status of the thing-in-itself is particularly relevant to the formulation of his own philosophy. For this reason, Nietzsche's comprehension of this problem has also become one of the most debated and

* Professor Adjunto da Universidade Federal do Recôncavo da Bahia (UFRB). Artigo recebido em 15/07/2013 e aprovado em 28/10/2013. 
controversial subjects among his interpreters. There is a general trend among them to identify in Nietzsche's philosophy a path that would lead him from the assumption of a concept of thing-in-itself in his youth to a denial of the thing-in-itself, in his late philosophy, what is regarded as a contradictory conception. The disagreement among them takes place when it is called into question if the concept of thing-in-itself that Nietzsche denies is exactly what Kant meant by thing-in-itself. My purpose is to discuss this issue by means of a study of three objections made by Nietzsche to the concept of thing-in-itself, taking the historical aspects of the problem, as well as the solutions offered by the secondary literature, into consideration.

Keywords Nietzsche, Kant, thing-in-itself.

\section{Introdução}

Investigar os comentários de Nietzsche à noção de coisa em si significa retomar um problema tradicional tanto no âmbito da filosofia de Kant quanto no da obra de Nietzsche. Em ambos os casos, estamos diante de uma questão complexa e multifacetada, que, de um lado, é central para o empreendimento de ambos os filósofos; de outro, representa, por isso mesmo, um palco de controvérsias entre os comentadores das obras de Kant e Nietzsche. A discussão dessa questão necessita, desse modo, do ponto de vista histórico, da compreensão prévia dessas controvérsias, e, do ponto de vista sistemático, de uma tomada de posição em relação ao significado da noção de coisa em si em ambos os casos. Sem isso, torna-se difícil avaliar a pertinência da abordagem de Nietzsche do conceito kantiano de coisa em si.

A esse respeito, não há dúvida de que, entre os temas kantianos discutidos por Nietzsche, a questão sobre o estatuto da coisa em si é particularmente relevante para a elaboração de sua própria filosofia, já que ela tem como um dos seus objetivos, em sua forma madura, a crítica à noção de uma realidade independente de qualquer perspectiva. Por esse motivo, a compreensão de Nietzsche desse problema também se tornou um dos assuntos mais debatidos e controversos entre seus intérpretes. De forma geral, e com naturais diferenças de ênfase, os comentadores tendem a identificar na filosofia de Nietzsche uma trajetória que o levaria da admissão de um conceito de coisa em si em sua juventude até uma negação da coisa em si, considerada como uma concepção contraditória, em sua filosofia madura. A discordância entre os comentadores surge quando se pergunta se o conceito de coisa em si que Nietzsche critica 
é exatamente aquilo que Kant entendia por coisa em si. ${ }^{1}$ Para resolver essa questão, deveremos apresentar as diversas formas pelas quais o conceito kantiano de coisa em si pode ser entendido, para em seguida verificar se as críticas de Nietzsche se aproximam de algum desses sentidos. Esse objetivo não pode ser minimamente alcançado sem o recurso a parte da extensa e complexa literatura secundária que esse tema deixou como herança, tanto na fortuna crítica de Kant quanto na de Nietzsche.

\section{Kant e a coisa em si}

A questão da coisa em si reveste-se para Kant de uma importância central na elaboração da sua filosofia crítica pelo fato de que a distinção entre os termos correlatos aparência/fenômeno e coisa em si/númeno/objeto transcendental será uma distinção relevante para o estabelecimento dos limites do conhecimento e para a identificação da ilusão transcendental. Para Kant, o problema central da metafísica que o antecedeu consistia na inobservância da distinção entre fenômeno e coisa em si, os âmbitos que eles encerram e a pertinência da aplicação de determinadas classes de conceitos a esses âmbitos. Por não ter observado os limites do conhecimento humano, a metafísica dogmática foi levada a deparar-se com problemas insolúveis, não conseguindo se estabelecer como um conhecimento seguro, já alcançado pela lógica, pela matemática e pela física. Sem a investigação dos âmbitos e limites do conhecimento proposta por uma crítica da razão pura, a metafísica continuaria a avançar para além do âmbito de objetos passíveis de conhecimento, supondo conhecer as coisas em si mesmas, objetos que transcendem o âmbito da experiência possível, sem reconhecer as distintas esferas de aplicação dos conceitos puros do entendimento e das ideias da razão (Kant, 2008b, pp. 111-112/Prol. § 41). ${ }^{2}$

Se o que acabamos de expor pode ser considerado ponto minimamente pacífico para qualquer leitor de Kant, o mesmo não pode ser dito, contudo, do significado da distinção entre coisa em si e fenômeno. Podemos identificar, em um apanhado que não pretende nem pode ser exaustivo, pelo menos cinco maneiras de entender a relação entre fenômeno e coisa em si: 1. como uma distinção entre âmbitos e objetos ontologicamente distintos: um mundo

1 Entre outros, os seguintes autores já se debruçaram sobre a relação entre Nietzsche e o conceito de coisa em si: Riccardi (2009, 2010); Houlgate (1993); Salaquarda (1978); Stack (1983).

2 Nas referências às obras de Kant, além da paginação da edição utilizada, indicaremos a obra e a página das edições originais, no caso da primeira e segunda críticas, e o parágrafo, no caso dos "Prolegômenos", utilizando as seguintes abreviaturas: Prol, "Prolegômenos"; CRP, "Crítica da razão pura"; CRPr, "Crítica da razão prática”. 
sensível e um mundo inteligível, sendo a coisa em si causa ou fundamento do fenômeno; ${ }^{3}$ 2. como duas espécies de objetos distintos: as coisas e as representações das coisas; ${ }^{4}$ 3. como uma distinção semântica entre dois conceitos $;{ }^{5}$ 4. como duas considerações transcendentais a respeito do mesmo objeto (quando submetido às condições epistêmicas e quando abstraídas essas condições); ${ }^{6}$ 5. como uma distinção metafísica, na qual o mesmo objeto é considerado a partir das propriedades intrínsecas ou das propriedades extrínsecas de uma substância. ${ }^{7}$

Como cada uma dessas interpretações e distinções é, em diferentes medidas, defensável a partir dos próprios textos de Kant, fica explícito como cada uma delas depende da compreensão do empreendimento crítico como um todo. Mas, para além dessas diversas formas de compreender a distinção entre fenômeno e coisa em si, podemos reter três distinções mais gerais que, relacionadas intimamente entre si, são importantes para avaliar a abordagem de Nietzsche da coisa em si e seus desdobramentos: 1. a distinção entre a interpretação de dois mundos e de dois aspectos; ${ }^{8}$ 2. a distinção entre os sentidos positivo e negativo de númeno; ${ }^{9} 3$. a distinção entre a coisa em si compreendida dos pontos de vista teórico e prático. ${ }^{10}$ Assim, para o diálogo

3 A formulação clássica dessa compreensão encontra-se em F. H. Jacobi (Cf. Jacobi, 1992, p. 106).

4 É a maneira pela qual Paul Guyer compreende a oposição entre coisa em si e fenômeno: "Kant não precisa postular um segundo conjunto de objetos além daquele a que nos referimos ordinariamente, a fim de tirar o tempo e espaço das coisas como elas são em si mesmas, [...] porque a ontologia que com ele começa já inclui duas classes de objetos, a saber, coisas como mesas e cadeiras e nossas representações delas" (Guyer, 1987, p. 335).

5 Henry Allison atribui essa interpretação a Erich Adickes: "Outras passagens sugerem que a declaração de Kant é semântica. Nessa leitura, Kant está afirmando uma relação de implicação lógica entre um conceito de um fenômeno e um conceito de uma coisa como ela é em si mesma" (Allison, 1983, p. 240).

6 Posição defendida por Allison: "Considerar as coisas como elas aparecem [...] é considerá-las em sua relação com as condições sensíveis sob as quais elas nos são dadas à mente na intuição. Do mesmo modo, considerá-las como elas são em si mesmas é pensar nelas independentemente de todas as referências a essas condições" (Allison, 1983, p. 241).

7 Distinção sugerida por Rae Langton: "Considerada dessa forma, a distinção de Kant ente fenômeno e coisa em si está bem distante de ser uma distinção fenomenalística entre representações mentais e coisas independentes da mente. Ela pode ser assim resumida:

Distinção: Coisas em si são substâncias que possuem propriedades intrínsecas; fenômenos são propriedades relacionais de substâncias" (Langton, 1998, p. 20).

8 Como vimos, Jacobi defende uma teoria de dois mundos; Allison defende uma teoria de dois aspectos.

9 Não discutiremos aqui a distinção, nem sempre consistente nos próprios textos de Kant, entre aparência (Erscheinung), fenômeno (Phaenomenon), de um lado, e coisa em si, númeno e objeto transcendental, de outro, como o faz Allison, ao conceber aparência enquanto um objeto indeterminado de uma intuição e fenômeno enquanto um objeto determinado pelas condições formais transcendentais; a coisa em si como um objeto indeterminado abstraído das condições formais transcendentais, objeto transcendental como um algo $=x$ pressuposto em toda intuição, e númeno, negativamente, como um conceito-limite, como um ente pensado como não sendo um objeto de uma intuição sensível, e positivamente, como um ente pensado como o objeto de uma intuição não sensível (Cf. Allison, 1983, pp. 244-245).

10 Tanto Allison quanto Houlgate sustentam que pelo menos no sentido prático a distinção ontológica entre númeno e fenômeno é necessária: "A concepção de um númeno como uma entidade ontologicamente distinta só é requerida para permitir a possibilidade de conceber Deus (e talvez almas racionais). Esta 
entre Nietzsche e Kant que estabeleceremos aqui, será necessário levar em conta essas distinções.

\section{Nietzsche e a crítica à coisa em si}

Em termos cronológicos, há uma periodização possível das abordagens de Nietzsche sobre a coisa em si, compartilhada por vários comentadores, e que recebeu o que poderíamos chamar de sua forma canônica na obra de Maudemarie Clark, "Nietzsche on truth and philosophy" (Clark, 1990), na qual a autora identifica três momentos na obra de Nietzsche: 1 . o período de "O nascimento da tragédia" e de "Verdade e mentira em sentido extramoral", quando Nietzsche pressupõe a existência da coisa em si; 2. entre "Humano, demasiado humano" e "A gaia ciência", quando Nietzsche assume um agnosticismo em relação à coisa em si, embora ainda permaneça com uma teoria da falsificação - ou seja, que nossos conceitos falsificam a realidade -, o que acaba por dar margem a uma permanência sub-reptícia da coisa em si; 3. o último período de sua filosofia, com a refutação definitiva da coisa em si como um conceito contraditório, o que só seria possível com o abandono da teoria da falsificação e a adoção do perspectivismo. ${ }^{11}$ Essa periodização será aqui adotada metodologicamente, a fim de nos concentrarmos no último período e assim avaliarmos as críticas de Nietzsche à coisa em si.

Nesse contexto, é importante observar que Nietzsche herda a problemática da coisa em si no interior de uma teoria de dois mundos e da discussão do problema da afecção, como já aparecia em Jacobi. Assim, sua primeira objeção à coisa em si repercutirá uma crítica tradicional a Kant, segundo a qual este não teria tido direito, a partir da própria filosofia crítica, a sustentar a existência de uma coisa em si como causa do fenômeno, já que a categoria de causalidade só se aplicaria ao âmbito da experiência possível:

concepção é, portanto, importante para a metafísica de Kant, incluindo sua metafísica da moral, mas ela não se insere diretamente em uma abordagem transcendental das condições de possibilidade do conhecimento humano" (Allison, 1983, p. 239). Houlgate: "O conceito de Kant de coisa em si, o 'númeno' ou o 'objeto transcendental' - esses termos são de fato intercambiáveis - possui duas funções distintas. De um lado, ele permite a Kant traçar uma distinção entre os objetos finitos que experimentamos e os objetos incondicionados, 'infinitos', tais como Deus e a alma, que, ele sustenta, não experimentamos" (Houlgate, 1993, p. 121).

11 Para ser mais preciso, para Clark os elementos de superação da coisa em si já se encontram em "A gaia ciência" (§54 e § 58), mas só serão definitivamente efetivos quando Nietzsche desenvolver seu perspectivismo e abandonar a teoria da falsificação, o que só ocorreria após a "Genealogia da moral". Para uma discussão detalhada sobre isso, ver Riccardi (2010). 
Kant não tinha mais direito à sua distinção entre 'coisa em si' e 'fenômeno' - ele havia se privado do direito de ainda distinguir dessa forma antiga e habitual, na medida em que ele rejeitou, como inadmissível, a inferência do fenômeno a uma causa do fenômeno - de acordo com sua compreensão do conceito de causalidade e de sua validade puramente intrafenomenal: essa compreensão, por outro lado, já pressupunha essa distinção, como se 'a coisa em si' não fosse apenas inferida, mas dada. (Nietzsche, 1988, vol. 12, p. 186. Fragmento 5[4]) ${ }^{12}$

Kant teria postulado injustificadamente um mundo de entidades distintas dos fenômenos, as coisas em si, tomando-as como causas dos fenômenos, depois de ter assegurado a impossibilidade de ter um conhecimento que transcendesse o âmbito fenomênico. Para isso, teria aplicado uma categoria ao âmbito da coisa em si, o que não seria permitido, já que uma das bases do idealismo transcendental consiste justamente no impedimento da aplicação dos conceitos do entendimento a objetos que transcendem o âmbito da experiência. Em contrapartida, ao conceber uma relação de causalidade entre coisa em si e fenômeno, Kant já teria, de antemão, considerado a coisa em si não apenas como o resultado de uma inferência, mas também a dotado de uma existência previamente dada.

Kant, de fato, refere-se em vários momentos de sua obra à coisa em si como causa ou fundamento do fenômeno. ${ }^{13}$ Do mesmo modo, ele também dá a entender que haveria um âmbito de objetos inteligíveis, um mundo inteligível, contraposto ao mundo das coisas que nos aparecem. Mas essa interpretação, que pressupõe a existência de duas entidades ontologicamente distintas, poderia muito bem ser apenas uma leitura exageradamente literal desses trechos, ocasionada por uma incompreensão de fundo de alguns aspectos sutis do idealismo transcendental, pois há também inúmeras passagens, inclusive no "Opus postumum", em que Kant explicitamente rechaça essa interpretação, defendendo o que se passou a denominar uma teoria dos dois aspectos, ou seja, que coisa em si e fenômeno são duas maneiras distintas de considerar o mesmo objeto, a depender de que se levem em conta ou não as condições formais a priori. ${ }^{14}$

12 Indicaremos, nas obras de Nietzsche, além da referência ao volume e página da KSA, a obra, sua seção e/ou seu parágrafo, no caso dos textos publicados, e o número dos fragmentos, no caso dos póstumos.

13 Essas passagens de Kant são bem conhecidas, por exemplo: CRP, B xxvi, A 288; Prol, § 13 , § 32.

14 "Devemos, com respeito à intuição de um objeto no espaço ou no tempo, sempre fazer a distinção entre a representação da coisa em si mesma e daquela mesma coisa como aparência - embora não possamos atribuir à primeira atributos, mas, como um $=x$, podemos vê-la apenas como um correlato para o entendimento puro (como cogitabile, não dabile) em que conceitos, não coisas, são contrastados uns com outros. A proposição: todos os objetos sensíveis são coisas que aparecem (objecta phaenomena) aos quais corresponde um númeno como o fundamento de sua coordenação; mas nenhuma intuição 
Nessas passagens, Kant esclarece em que sentido deveria ser entendida a relação entre coisa em si e fenômeno, assim como a afirmação de que podemos considerar a coisa em si como causa do fenômeno. Sendo absurdo falar de aparência sem algo que aparece, e sendo ao mesmo tempo interditada a atribuição positiva de propriedades a esse algo, a coisa em si é um nome para expressar um algo $=\mathrm{x}$, sobre o qual nada podemos conhecer, mas sobre o qual podemos pensar, já que, para isso, é necessário apenas que não se viole o princípio de não contradição. Trata-se, assim, apenas de uma possibilidade lógica. Nesse sentido, a coisa em si seria meramente um ens rationis, um ente do pensamento, cuja existência real é problemática, ou seja, apenas passível de ser pensada sem contradição. Falar de coisas em si não seria, desse modo, uma posição dogmática e contraditória ao espírito do idealismo transcendental, mas uma consequência desse próprio idealismo.

Há uma diferença entre a categoria como um conceito puro do entendimento, alcançado por meio da função unificadora dos juízos, e portanto um conceito vazio de conteúdo, e o uso das categorias já esquematizadas e desse modo aplicadas a uma intuição sensível no âmbito da experiência. Somente no âmbito do uso empírico, remetidas a intuições que conferem conteúdo às representações, as categorias referem-se objetivamente a fenômenos. Em um uso meramente lógico, podemos pensar em uma coisa em si como causa ou fundamento do fenômeno, já que não faz sentido falar de aparência sem algo que aparece. ${ }^{15}$ Mesmo que venhamos a pressupor a existência de tal objeto, isso não implica que tenhamos conhecimento dele. Posso até afirmar que, possuindo uma faculdade receptiva, a sensibilidade, tenho de pressupor o conceito desse objeto que me afeta, produzindo minhas representações, embora não possa assegurar sua realidade objetiva. ${ }^{16}$ Embora Kant de fato refira-se à coisa em si como causa ou fundamento do fenômeno, pode-se sustentar que ele não transcende o limite da experiência possível nem utiliza de maneira inconsistente a categoria de causalidade, como é levantado por essa objeção tradicional, repetida aqui por Nietzsche. Isso porque esse uso seria meramente lógico, e não uma aplicação de um conceito limitado à experiência a um objeto transcendente.

particular (no noumenon aspectabile) corresponde ao último, pois isso seria uma contradição com respeito ao elemento subjetivo do princípio" (Kant, 1993, p. 174).

15 A coisa em si seria, desse modo, um conceito alcançado analiticamente: ela significa apenas o mesmo objeto considerado a partir da abstração das condições transcendentais. Mais uma vez, não se está afirmando aqui o conhecimento da coisa em si que causaria o fenômeno; estamos apenas pensando em sua possibilidade, em um juízo analítico, o que me é permitido, já que pensado sem contradição.

16 Cf. Allison, 1983, p. 254. 
Sendo assim, na passagem de Nietzsche citada, o que parece ser uma objeção mais pertinente não é a crítica a uma aplicação indevida da categoria de causalidade, mas ao próprio pressuposto da existência da coisa em si, o que será desenvolvido em sua segunda e terceira objeções.

A segunda objeção de Nietzsche é que Kant teria ultrapassado os limites da crítica, ao considerar a coisa em si como a essência do fenômeno, quando a própria distinção entre uma coisa e sua essência deveria ser justificada: ${ }^{17}$

Pouco me importa se alguém, com a modéstia do ceticismo filosófico ou com a humildade religiosa, diga: 'a essência das coisas me é desconhecida' ou outro, mais corajoso, mas ainda pouco versado em crítica e desconfiança: 'a essência das coisas me é em grande parte desconhecida'. Diante de ambos afirmo que eles, sob todos os aspectos, pensam que sabem, imaginam que sabem demais, ou seja, como se a distinção que ambos pressupõem, entre uma 'essência das coisas' e um mundo fenomênico, fosse correta. (Nietzsche, 1988, vol. 12, pp. 240-241. Fragmento 6[23])

Segundo Nietzsche, para que se possa distinguir entre o fenômeno e a essência das coisas, seria necessário situar-se em um ponto exterior às aparências, ponto de vista a partir do qual se poderia saber que há propriedades das coisas que lhes são inerentes. Uma coisa em si seria, segundo essa interpretação, uma "constituição absoluta das coisas" (Nietzsche, 1988, vol. 12, p. 351. Fragmento 9[35]). Mas o próprio Kant já tinha limitado nosso conhecimento às nossas faculdades, de sorte que falar de coisas em si como se se tratasse da essência de uma coisa já seria entrar em contradição com os próprios pressupostos da crítica:

Para poder fazer tal distinção [entre a "essência das coisas" e seu fenômeno], ter-se-ia de se pensar nosso intelecto possuindo um caráter contraditório: primeiro, preparado para o olhar perspectivo, como é necessário para seres de nossa espécie poderem manter-se na existência, de outro lado, simultaneamente, uma faculdade de perceber esse olhar perspectivo como perspectivo, o fenômeno como fenômeno. (Nietzsche 1988, vol. 12, pp. 240-241. Fragmento 6[23])

Afirmar que existe a essência de um fenômeno significa, para Nietzsche, colocar-se em um ponto exterior a todas as perspectivas. ${ }^{18}$ A essência de uma

17 Para Nietzsche, falar de uma coisa já é pressupor a ideia de substância, que, por sua vez, é uma projeção da crença num sujeito metafísico: "[A consciência] acredita no 'eu', no eu como ser, no eu como substância e projeta a crença no eu-substância em todas as coisas - ela cria assim o conceito 'coisa'..." (Nietzsche, 1988, vol. 6, p. 77. "Crepúsculo dos ídolos", A razão na Filosofia, § 5). Uma coisa em si, por sua vez, seria uma substância concebida em suas propriedades essenciais, diferentemente da forma como ela se nos apresenta, ou seja, ela seria independente de toda perspectiva.

18 "O intelecto não pode criticar a si mesmo, simplesmente porque ele não pode se comparar com outras espécies de intelecto e porque sua faculdade de conhecer só se revelaria na presença da 'realidade 
coisa não pode ser isolada das perspectivas; pelo contrário, ela só pode ser pensada como já constituída de perspectivas, e não como se a coisa em si fosse uma espécie de substância metafísica, independente de qualquer relação. Para Nietzsche, não podemos afirmar que haja uma coisa em si, como não podemos afirmar que haja um "sentido em si" ou um "significado em si", pois qualquer significação já é uma significação posta por uma perspectiva: "A 'essência', a 'essencialidade' é algo perspectivo" (Nietzsche, 1988, vol. 12, p. 140. Fragmento 2[149]). Nessa segunda objeção, Nietzsche defende que não temos como supor que, além do fenômeno, possamos pensar em algo, e muito menos no que seriam suas propriedades intrínsecas. Ao aventar a possibilidade de coisas em si em oposição aos fenômenos, Kant já estaria pressupondo conhecer algo mais do que seu próprio agnosticismo permitiria: que há coisas, e que essas coisas, em si mesmas, possuem propriedades essenciais.

Compreender a coisa em si como essência do fenômeno é uma interpretação que Nietzsche herda, entre outros, de Schopenhauer e Lange. Pode-se, é verdade, sustentar que Kant entende as coisas em si como substâncias, consideradas a partir de suas propriedades intrínsecas. Mas, mesmo neste caso, ele não estaria ultrapassando os limites da crítica, pois mais uma vez a coisa em si pode ser pensada sem contradição como uma substância: logicamente, enquanto um primeiro sujeito de toda predicação; ontologicamente, enquanto suporte de propriedades intrínsecas, e não como a categoria esquematizada de substância. ${ }^{19} \mathrm{O}$ cerne da segunda crítica de Nietzsche consiste em mostrar que a afirmação de que as coisas em si possuem propriedades intrínsecas é uma tese dogmática, já que pressupõe um ponto exterior a todas as perspectivas. Contudo, pode-se novamente sustentar que Kant está afirmando apenas a possibilidade lógica, e não sua realidade objetiva. Apesar disso, essa segunda crítica de Nietzsche aponta para um passo fundamental para sua terceira objeção, a saber, que a coisa em si seria um conceito contraditório, por postular a existência de uma coisa que seja

verdadeira', isto é, para criticar o intelecto, teríamos de ser uma entidade superior com 'conhecimento absoluto'" (Nietzsche, 1988, vol. 12, p. 188. Fragmento 5[11]).

19 Essa é a linha de argumentação de Langton (1998), baseada sobretudo na discussão de Kant com Leibniz na Anfibologia (Kant, 1997, pp. 274-294/CRP, B324-349). Em várias passagens desse capítulo da "Crítica da razão pura", Kant parece de fato concordar que a coisa em si possa ser identificada com a substantia noumenon metafísica, ou seja, um primeiro sujeito de toda predicação, que, ontologicamente, seria depositário de propriedades intrínsecas, em contraposição às propriedades extrínsecas, relacionais, que constituem os fenômenos. Assim, a distinção entre coisa em si e fenômeno seria uma distinção eminentemente metafísica, e não fenomenológica ou epistemológica. E também não seria uma utilização indevida da categoria de substância, já que aqui não se trataria do conceito de substância da primeira analogia, que também pressupõe a categoria já esquematizada, a substantia phaenomenon (um fenômeno que só comparativamente, e não absolutamente, pode ser considerado substância), mas sim também de um uso lógico dessa categoria. O erro do metafísico seria aplicar esse conceito aos fenômenos. 
independente de qualquer relação, quando, para Nietzsche, o próprio conceito de coisa significa ser constituído por relações. Para Nietzsche, assim, seria logicamente impossível formular o conceito de coisa em si.

Nessa terceira objeção de Nietzsche, o que é criticado em Kant não é apenas a possibilidade de termos um ponto exterior de observação, mas também a própria possibilidade lógica de se pensar significativamente em uma coisa em si, ou seja, uma coisa cujas propriedades são independentes de qualquer relação. Assim, se a própria noção de coisa já é produto de perspectivas, a ideia de uma coisa em si, como uma substância independente de todas as perspectivas seria não apenas uma ficção, mas uma ficção absurda: "A 'coisa' é uma ficção, a 'coisa em si', além disso, uma ficção contraditória" (Nietzsche, 1988, vol. 11, p. 614. Fragmento 38[14]). ${ }^{20}$ Isso porque, para Nietzsche, a própria noção de coisa é definida como o resultado de relações: “As propriedades de uma coisa são efeitos sobre outras 'coisas'; se se abstraem as outras 'coisas', então uma coisa não possui nenhuma propriedade, isto é, não existe uma coisa sem outras coisas, isto é, não existe nenhuma 'coisa em si'" (Nietzsche, 1988, vol. 12, p. 104. Fragmento 2[85]). Em outras palavras, Nietzsche discorda que possamos sequer pensar em algo que já não esteja relacionado e não seja produzido por essas relações. Pensar em uma coisa em si seria por isso contraditório, absurdo: “A 'coisa em si' é um absurdo (widersininig) Quando eu abstraio todas as relações, todas 'propriedades', todas 'atividades' de uma coisa, então não resta a coisa" (Nietzsche, 1988, vol. 12, p. 580. Fragmento 10[202]).

Com isso, Nietzsche sem dúvida está levando ao extremo uma leitura de caráter kantiano, adotando assim uma versão inflada da noção negativa de númeno, como um conceito-limite. Nietzsche estaria aqui traçando uma consequência extremada da própria doutrina kantiana, segundo a qual o conceito negativo de númeno serve como limite do que pode ser pensado significativamente. Kant atribuiu à coisa em si o estatuto de um conceito problemático, ou seja, apenas logicamente possível. Mas Nietzsche não considera esse conceito sequer problemático, mas simplesmente absurdo. Sendo o conceito de coisa em si um absurdo, Kant é assim censurado por não ter levado a termo seus próprios pressupostos. Kant não teria visto que a concepção de uma coisa da qual sabemos apenas que dela nada podemos saber é algo que contradiria a própria razão:

20 A leitura de Lange sem dúvida contribui para a formulação dessa crítica de Nietzsche. Para Lange, Kant não teria levado às últimas consequências seu ficcionalismo, atribuindo um estatuto positivo a conceitos poéticos, ficções úteis para o âmbito prático (Lange, 1974, p. 509). Para Nietzsche, contudo, a coisa em si não é sequer uma ficção, mas um absurdo. 
[...] [M] esmo no conceito kantiano de 'caráter inteligível das coisas' resta ainda algo desta lasciva desarmonia de ascetas, que adora voltar a razão contra a razão: pois 'caráter inteligível' significa, em Kant, um modo de constituição das coisas do qual o intelecto compreende apenas que é, para o intelecto, absolutamente incompreensível. (Nietzsche, 1988, vol. 5, p. 364. "Genealogia da moral”, III, § 12)

Estas são, portanto, as principais objeções de Nietzsche à noção de coisa em si em Kant: 1. trata-se de um uso indevido da categoria de causalidade; 2. é concebida, de forma injustificada, como uma essência metafísica das coisas; 3 . é um conceito contraditório, pois pressupõe uma coisa independente de qualquer relação. Como cada interpretação do estatuto da coisa em si em Kant depende de uma leitura particular do idealismo transcendental, o mesmo ocorre com a interpretação de Nietzsche. Até o momento, vimos as críticas de Nietzsche à noção de coisa em si em seu aspecto teórico. Mas para entender o papel que o projeto kantiano como um todo desempenha na abordagem de Nietzsche do conceito de coisa em si é necessário levar em consideração as três distinções a que fizemos alusão no início de nosso texto: 1. a distinção entre a interpretação de dois mundos e de dois aspectos; 2. a distinção entre os sentidos positivo e negativo de númeno; 3. a distinção entre a coisa em si compreendida dos pontos de vista teórico e prático.

No primeiro caso, Nietzsche interpreta a relação entre coisa em si e fenômeno como uma relação entre dois âmbitos distintos, como um mundo inteligível e um mundo sensível, reproduzindo assim a distinção que, para ele, marca a metafísica desde Platão. Contemporaneamente, a teoria de dois aspectos tomou destaque nos estudos kantianos, o que não quer dizer, como já vimos, que a concepção de dois mundos seja inteiramente absurda e sem base textual. Na realidade, se considerarmos a coisa em si em seu aspecto teórico, a leitura de dois aspectos parece ter mais suporte textual; se atentarmos, contudo, ao seu uso prático, veremos que a leitura de dois mundos se torna mais plausível. Em relação ao aspecto prático do conceito de coisa em si, Nietzsche é claro no texto "Como o 'mundo verdadeiro' enfim se tornou uma fábula”, do "Crepúsculo dos ídolos":

3. O mundo verdadeiro, inalcançável, indemonstrável, impossível de ser prometido, mas, já enquanto pensamento, um consolo, uma obrigação, um imperativo.

(O velho sol, no fundo, mas através de neblina e ceticismo; a ideia tornada sublime, pálida, nórdica, königsberguiana). (Nietzsche, 1988, vol. 6, p. 80)

Nessa passagem, Nietzsche acusa Kant de manter uma distinção que tem sua origem no platonismo, ao estabelecer a possibilidade de distinguir entre fenômenos (entes aparentes, "mundo aparente") e númenos (entes inteligíveis, 
"mundo verdadeiro"). A própria distinção entre o que pode ser conhecido e o que pode ser pensado já é, para Nietzsche, uma cisão entre dois âmbitos radicalmente distintos. O argumento de Nietzsche é que Kant, diante da ameaça do ceticismo e da necessidade de preservar o âmbito prático, teve de negar o acesso teórico ao "mundo verdadeiro" da coisa em si, para preservar os artigos de fé do âmbito prático, como Deus, liberdade e imortalidade da alma: 'Para criar um espaço para seu 'reino moral', [Kant] se viu obrigado a postular um mundo indemonstrável, um 'além' lógico, - justamente para isso foi necessária sua crítica da razão pura" (Nietzsche, 1988, vol. 3, p. 14. "Aurora", Prólogo, § 3). Por isso Nietzsche nega a coisa em si como possibilidade lógica: se se abrisse essa possibilidade, nada impediria que pudéssemos pensar em um reino moral numênico. Assim, por mais que a teoria de dois mundos que Nietzsche atribui a Kant possa para muitos não ser sustentável no âmbito teórico, ela aponta para uma faceta indiscutível da obra de Kant, que é o retorno do númeno no âmbito prático, quando ele postula, por exemplo, na passagem do âmbito teórico ao prático, com o conceito de liberdade transcendental, a distinção entre o caráter inteligível e o empírico de um agente, e, já no âmbito propriamente prático, a pressuposição de uma comunidade de seres inteligíveis como condição para a realização da ação moral.

Kant havia distinguido os sentidos positivo e negativo de númeno, descartando o positivo, já que pressuporia uma intuição intelectual, e considerando o negativo como uma possibilidade lógica e uma garantia dos limites que não poderiam ser transpostos. Mas há uma terceira distinção no interior do próprio conceito amplo de coisa em si, entre objetos de conhecimento, aos quais se aplica com justeza o sentido negativo, e objetos que não possuem uma manifestação fenomênica, e que no entanto são centrais no âmbito prático. Esses dois sentidos (teórico e prático) são claramente distinguidos na segunda crítica. De fato, na "Crítica da razão prática” Kant revela como seu intuito na primeira crítica tinha sido reservar um espaço para que os númenos não fossem considerados mera ficção, deixando lugar assim para seu uso legítimo no âmbito prático na segunda crítica, onde o suprassensível, interditado na primeira crítica, encontra seu lugar:

Aqui se ilustra primeiramente também o enigma da crítica: como se pode negar realidade objectiva ao uso supra-sensível das categorias na especulação e concederlhes, no entanto, esta realidade relativamente aos objetos [Objekte] da razão pura prática. (Kant, 2008a, p. 14/CRPr, A 8)

Uma vez que esta [a crítica especulativa] recomendava admitir os objetos da experiência como tais e, entre eles, mesmo o nosso próprio sujeito, unicamente como 
fenómenos, pondo-lhes, no entanto, como fundamentos coisas em si; portanto, não considerar todo o supra-sensível como uma ficção e o seu conceito como vazio de conteúdo, agora, a razão prática, por si mesma e sem se ter associado com a [razão] especulativa, confere realidade a um objeto [Gegenstand] supra-sensível da categoria da causalidade, a saber, a liberdade (embora seja um conceito prático e apenas para uso prático), por conseguinte, aquilo que lá [no domínio da razão especulativa] podia simplesmente ser pensado é confirmado por um fato [Faktum]. (Kant, 2008a, p. 14/ CRPr, A9; tradução modificada)

Notemos que Nietzsche aqui não está acusando Kant de nenhum tipo de contradição interna no projeto crítico. Ele compreende muito bem que as ideias da razão são pensadas apenas enquanto conceitos práticos, e que portanto são restritas a esse âmbito. A crítica de Nietzsche consiste no fato de que, assim, Kant teria postulado um valor positivo à coisa em si, que viria, de uma forma sofisticada, retomar os conceitos metafísicos tradicionais, fornecendo uma nova força e um novo alento à metafísica que Kant procurava superar. $^{21}$

De um lado, esse era de fato o objetivo explícito do empreendimento crítico. Nietzsche lembra, por mais de uma vez, a famosa passagem do prefácio da segunda edição da "Crítica da razão pura" em que Kant afirma ter tido de suprimir o saber para dar lugar à fé. ${ }^{22}$ De outro, Nietzsche não é inteiramente original nessa crítica ao aspecto prático do projeto crítico e do retorno à metafísica. Mas o mais importante nessa discussão é perceber que Nietzsche acompanha até certo ponto o conceito de coisa em si como conceito-limite, distanciando-se de Kant justamente no momento em que ele se torna passível de uma leitura positiva, seja no âmbito teórico, quando Kant não teria avançado o suficiente, para que considerasse o próprio conceito como contraditório, e principalmente no âmbito prático, quando Kant lhe fornece um estatuto positivo. Em suma, apesar da crítica generalizada à coisa em si, o acento de Nietzsche recai sobre a possibilidade de uso prático desse conceito, o que

21 A possibilidade de levantar essa questão é a principal conclusão do texto de Lebrun, "A aporética da coisa em si" (Lebrun, 2012, pp. 53-71). Allen Wood, embora advirta que Kant não pretende com a postulação de um "mundo numênico" fazer qualquer afirmação positiva sobre seu conhecimento ou sua existência, nem que isso implica um isolamento da questão moral meramente a um mundo transcendente, admite que Kant em alguns momentos dá a entender isso: "Infelizmente, em algumas passagens parece que o próprio Kant quer fazer um uso positivo da liberdade numênica - como ainda outra prova indireta do idealismo transcendental (KpV 5:100-3), ou alguma forma de aviso (intimation) (ou mesmo cognição) de nossa participação em um mundo supranatural para além do mundo dos sentidos (G 4:451-3, KpV 5:105). Aparentemente, Kant também considera moralmente adequado que, como frequentemente nós pensamos nos seres humanos como fins em si mesmos, possuindo valor e dignidades absolutos, temos de também pensar neles como tendo um destino supranatural (ou numênico), colocando-os fora de todos esses seres inferiores cujo fado é ser mera parte da natureza" (Wood, 2008, p. 138).

22 Nietzsche, 1988, vol. 3, p. 172. "Aurora", § 197; vol. 7, pp. 426-427. Fragmento 19[34]; vol. 5, p. 16. "Além do bem e do mal", § 2 . 
permitiria o retorno a artigos de fé que teriam sido efetivamente abandonados se Kant tivesse estendido radicalmente sua concepção teórica de coisa em si e compreendesse que, no fundo, se trata de um conceito contraditório, servindo apenas como limite do que pode ser afirmado significativamente.

\section{Referências}

ALLISON, H. "Kant's transcendental idealism". New Haven: Yale University Press. 1983.

CLARK, M. "Nietzsche on truth and philosophy". New York: Cambridge University Press, 1990.

GUYER, P. "Kant and the claims of knowledge". Cambridge: Cambridge University Press, 1987.

HOULGATE, S. "Kant, Nietzsche and the thing in itself". Nietzsche-Studien, 22, 1993.

JACOBI, F. H. "Sobre o idealismo transcendental”. In: Recepção da crítica da razão pura. Org. F. Gil. Lisboa: Calouste Gulbenkian, 1992.

KANT, I. "Crítica da razão prática". Tradução de A. Mourão. Lisboa: Edições 70, 2008a.

KANT, I. "Prolegômenos a toda a metafísica futura". Tradução de A. Mourão. Lisboa: Edições 70, 2008b.

KANT, I. "Crítica da razão pura". Tradução de M. P. dos Santos e A. F. Morujão. Lisboa: Calouste Gulbenkian, 1997.

KANT, I. “Opus postumum”. Cambridge: Cambridge University Press, 1993.

LANGE, F. A. "Geschichte des Materialismus". Frankfurt: Suhrkamp, 1974.

LANGTON, R. "Kantian humility. Our Ignorance of Things in Themselves". Oxford: Oxford University Press, 1998.

LEBRUN, G. "A aporética da coisa em si”. In: G. Lebrun. Sobre Kant. São Paulo: Iluminuras, 2012.

NIETZSCHE, F. "Sämtliche Werke. Kritische Studienausgabe". 15 vols. Berlim/ Munique: Walter de Gruyter/dtv, 1988.

RICCARDI, M. "Nietzsche's critique of Kant's thing in itself". Nietzsche-Studien, 39, 2010.

RICCARDI, M. “'Der faule Fleck des kantischen Kriticismus'. Erscheinung und Ding an sich bei Nietzsche". Basel: Schwabe, 2009.

SALAQUARDA, J. "Nietzsche und Lange". Nietzsche-Studien, 7, 1978.

STACK, G. "Lange and Nietzsche". Berlin: Walter de Gruyter, 1983.

WOOD, A. "Kantian ethics". New York: Cambridge University Press, 2008. 